\title{
Insulin Gene Therapy for Treating Type I Diabetes Mellitus: History, Progress and Future
}

\section{Challenges}

\author{
Tugce Akcan, Tausif Alam, and Hans W Sollinger* \\ Department of Surgery, University of Wisconsin-Madison School of Medicine and Public Health, USA
}

*Corresponding author: Hans W Sollinger, Department of Surgery, University of Wisconsin-Madison School of Medicine and Public Health, USA, Tel: 608-263-9903; E-mail: hans@surgery.wisc.edu

Received: 17 Sep, 2019 | Accepted: 11 Oct, 2019 | Published: 16 Oct, 2019

Citation: Akcan T, Alam T, Sollinger HW (2019) Insulin Gene Therapy for Treating Type I Diabetes Mellitus: History, Progress and Future Challenges. J Diab Res Ther 5(3): dx.doi.org/10.16966/2380-5544.148

Copyright: (C) 2019 Akcan T, et al. This is an open-access article distributed under the terms of the Creative Commons Attribution License, which permits unrestricted use, distribution, and reproduction in any medium, provided the original author and source are credited.

\begin{abstract}
Type 1 Diabetes Mellitus (T1DM) results from the autoimmune destruction of insulin-producing pancreatic $\beta$ cells. Despite advances in our understanding of both the pathogenesis and management of diabetes and treatment options, which mainly include injectable insulin and whole pancreas transplant, these advancements remain unsatisfactory and only a small portion of patients achieve their glycemic goals. Insulin gene therapy refers to the development of $\beta$ cell substitutes by introducing an insulin producing gene into endogenous cell populations that do not normally produce insulin. This strategy has the promise to overcome the limitations of current treatments. Here, we present an overview of the history of insulin gene therapy and review current achievements. We also briefly discuss areas for improvement and potential future directions.
\end{abstract}

Keywords: Gene therapy; Insulin; Type 1 diabetes mellitus; Adeno-associated virus

\section{Introduction}

Type I Diabetes Mellitus (T1DM), is a chronic disease caused by autoimmune destruction of insulin-producing pancreatic $\beta$ cells, resulting in progressive and irreversible failure of insulin production $[1,2]$. The National Diabetes Statistics Report estimated that about 1.25 million individuals in the U.S. are living with T1DM, including about 200,000 people aged $<20$ years and that each year approximately 40,000 individuals are diagnosed with T1DM [3]. The incidence of T1DM has been increasing dramatically and if this trend continues, 5 million people in the U.S. are expected to have T1DM by $2050[4,5]$. This increase has serious short-term and long-term health implications and will have a substantial impact on the cost of healthcare $[6,7]$.

Since the discovery of insulin by Banting FG and Best CH [8], exogenous insulin therapy has been the main treatment to control hyperglycemia in patients with T1DM. However, exogenous insulin treatment cannot quickly and accurately respond to fluctuations in blood glucose levels, resulting in both frequent hyperglycemic excursions and rarer but potentially life-threatening hypoglycemic events. $\beta$ cell replacement, either through solid pancreas transplantation or islet transplantation, can effectively control hyperglycemia, but the usefulness of this therapy is limited by the shortage of donor organs and the need for lifelong immunosuppression $[9,10]$. Several other therapies that do not rely on donor organs have been explored to improve diabetes therapy, including regeneration of $\beta$ cells. Unfortunately, most existing therapies fail to provide adequate control and much work still needs to be done to eliminate this disease [11].
Insulin gene therapy refers to the expression of the insulin gene in a cell type that does not ordinarily produce insulin, for the purpose of restoring euglycemia in diabetic patients. It is currently the most promising approach to accomplish a cure for T1DM in a safe, specific and efficient manner. However, mimicking some of the more complex aspects of insulin production and secretion in non- $\beta$ cells has remained a challenge.

The first challenge that must be surmounted is the production of functional insulin. Insulin is synthesized as a single-chain precursor, pre-proinsulin, consisting of A and B chains separated by a connecting (C)-peptide as well as a signal peptide. Cleavage of the signal peptide from pre-proinsulin yields proinsulin which undergoes further maturation through the proteolytic action of two specific prohormone convertases PC1/3 and PC2 [12,13]. Thus, in order for an insulin gene therapy to be successful, not only must the insulin gene be expressed, but it must also undergo appropriate post-translational processing. The prohormone convertases are only expressed in $\beta$ cells and other cells with the regulated secretory pathway, like pituitary cells and intestinal K cells [14]. Thus, insulin gene therapy strategies must either target cells that express the prohormone convertases endogenously, or use other approaches to circumvent the need for their activity.

The second major challenge is to achieve glucose-responsive secretion of insulin. Pancreatic $\beta$ cells have the ability to sense fluctuating levels of glucose through the activity of glucose transporter-2 (GLUT2) and glucokinase; and respond to physiological glucose concentrations by releasing premade insulin stored within secretory granules [15]. Both of these features are critical to the maintenance of euglycemia. Mimicking glucose-responsive insulin 
secretion achieved by $\beta$ cells remains a challenge for the field of insulin gene therapy.

Finally, the selection of an appropriate target cell and gene delivery vector remains key considerations.

In this review, we present an overview of insulin gene therapy and highlight the current state of this promising treatment. We also discuss the areas for improvement of present methodologies and potential future directions that will lead to safe and effective gene therapy approaches.

\section{Insulin Gene Therapy: a Historical Perspective}

The basic concept of gene therapy emerged in the 1960's as a consequence of major advancements in molecular biology and genetics that occurred at that time, which set the basis of molecular genetics and gene transfer. In 1963, Joshua Lederberg, a pioneer in molecular genetics, wrote in Biological Future of Man, "We might anticipate...the interchange of chromosomes and segments. The ultimate application of molecular biology would be the direct control of nucleotide sequences in human chromosomes, coupled with recognition, selection and integration of the desired genes. It will only be a matter of time before polynucleotide sequences can be grafted by chemical procedures onto a virus DNA" [16,17]. Shortly after cloning methods were developed, the first recombinant DNA human insulin was prepared by Goeddel DV [18] and colleagues at Genentech in 1978 by utilizing and combining the insulin A and B chains expressed in Escherichia coli. In 1982, human insulin became one of the first products of recombinant DNA technology, achieving FDA approval [19]. The demonstration that functional insulin could be produced in a non- $\beta$ cell from recombinant DNA formed the foundational evidence that a gene therapy for treating T1DM was possible.

The transfection of the insulin gene into somatic cells was first attempted in vitro in a monkey kidney cell line which resulted in the expression of proinsulin rather than functional, mature insulin, due to the lack of prohormone convertases [20,21]. In 1983, Moore HP, et al. [22] demonstrated correct conversion to native insulin by introducing human insulin cDNA in the mouse pituitary cell line AtT-20 derived from the anterior pituitary. AtT-20 cells share some features with the $\beta$ cells and contain prohormone convertases and secretory granules. The expression of insulin from AtT-20 cells provided proof of principle that non- $\beta$ cells could be modified to secrete insulin. Interestingly, in 1983, Nicolou and colleagues also presented results obtained in vivo after the injection of liposome-entrapped insulin cDNA and demonstrated successful insulin expression in the liver of rats [23]. In 1987, Selden $\mathrm{RF}$ and co-workers [24] described the implantation of fibroblasts expressing proinsulin under a metallothionein promoter in diabetic mice. These early experiments did not achieve perfect euglycemia; however, they were the foundation of subsequent studies.

In 1994, Valera A and colleagues [25] explored the possibility of using the liver as a target organ for insulin gene therapy by producing transgenic mice expressing the human proinsulin gene under the control of the liver-specific Phosphoenolpyruvate Carboxykinase (PEPCK) promoter. This experiment demonstrated that proinsulin can be produced by hepatocytes and can partially normalize blood glucose in diabetic mice. However, during these early experiments of insulin gene therapy, the scientific community already demanded the need for a regulated system of active and mature insulin production.

Despite failing to restore euglycemia in diabetic animals, these early studies signaled the feasibility of the overall approach, prompting further research to overcome the challenges of biologically active insulin being produced with regulated release from target cells.

\section{Production of biologically active insulin}

The molecular structure of functionally active insulin requires proteolytic cleavage of the precursor pre-proinsulin molecule at specific sites. Because the majority of cells lack the specific proteases required for insulin maturation, various groups have devised novel strategies to overcome this problem. The principal way to make active hormone has involved the introduction of proteolytic cleavage sites into the proinsulin molecule that are recognized by furin, a protease native too many tissues including hepatocytes. Furin recognizes the consensus cleavage site which consists of the amino acid residues, Arg-X-LysArg, which is absent in human proinsulin and exists in one copy in rat proinsulin. Gorman CM, et al. [26] used site-directed mutagenesis to introduce furin consensus cleavage sequences into human proinsulin cDNA. When transfected into transformed human kidney cells, the variant human proinsulin cDNA was processed into mature and functional human insulin. Receptor binding and autophosphorylation assays demonstrated that this insulin variant binds and activates the insulin receptor similarly to native insulin. The introduction of furin consensus sequences has been shown to increase the processing of proinsulin to insulin in a wide variety of non-neuroendocrine cells, including hepatocytes [27], fibroblasts [28], myoblasts [29].

\section{Glucose-responsive insulin transgene expression}

A major challenge for insulin gene therapy is the ability to synthesize and secrete insulin from non- $\beta$ cell types in response to changes in levels of glucose.

Pancreatic $\beta$ cells possess unique features that allow the regulation of insulin synthesis and secretion in response to physiological glucose concentrations. $\beta$ cells are able to monitor circulating glucose concentrations over a broad range of physiological concentrations (2-20 mM) through the activity of GLUT2 and glucokinase [30]. Similarly, hepatocytes, cells of the hypothalamus, and $\mathrm{K}$ cells of the small intestine all express GLUT2 or glucokinase, and can respond to fluctuations in blood glucose concentration [31]. $\beta$ cells also have control of insulin biosynthesis at the transcriptional, posttranscriptional, translational, and post-translational levels in response to glucose and other metabolites. Furthermore, $\beta$ cells, unlike other surrogate cells which have difficulty with secondary stimuluses, have the capacity to store insulin within secretory vesicles and generate secondary stimulus secretion coupling signals to activate rapid insulin exocytosis [32].

Because achieving glucose-responsive insulin release in non- $\beta$ cells has proven difficult, much attention has been focused on achieving glucose-responsive insulin production via regulation of transcription of the insulin transgene. For example, Glucose-inducible Response Elements (GIREs) are glucose-responsive DNA motifs found in the promoter region of glucose-inducible genes such as LPK, S14, fatty acid synthase, and acetyl-CoA carboxylase [33]. GIREs are composed of two tandem repeats of 5'-CACGTG known as E boxes, separated by $5 \mathrm{bp}$. When a specific transcription factor, Carbohydrate Response Element-binding Protein (ChREBP), recognizes E box sequences, it results in glucose-responsive control of gene transcription [34,35]. Subsequently, GIRE functions have been confirmed in primary cell culture and transgenic mice [36]. These experiments were the predecessor of many others that have been reported in the literature for successfully using GIREs in insulin gene therapy.

Alam T, et al. [37] reconstituted an insulin expression cassette containing GIREs from the S14 gene under the control of the liverspecific albumin promoter. The in vivo delivery of the insulin expression cassette by multiple vehicles including minicircle DNA [37], adenovirus, and lentivirus [38,39], to the livers of diabetic rats was 
studied as a potential method of correcting hyperglycemia. Delivery of the transgene resulted in restoration of normoglycemia, improved glucose tolerance, and normal rate of weight gain.

More studies on this system have been reported by Alam T, et al. [37]. They harnessed GIREs from the LPK gene to the liver-specific insulin-like Growth Factor Binding Protein-1 (IGFBP1) promoter and conferred a glucose-inducible, insulin-suppressible response following delivery to hepatocytes They demonstrated that injecting their insulin gene construct in Streptozotocin (STZ)-induced diabetic rats and mice resulted in restoration of near-normal glycemia $[40,41]$.

Han and coworkers generated a synthetic promoter (SP23137) containing GIREs. The reversal of hyperglycemia and improved glucose tolerance in STZ-induced diabetic mice following liverdirected adenoviral delivery was demonstrated [42]. Similarly, Zhang and Dong have cloned the GIREs from the promoter of the AcetylCoA Carboxylase (ACC) gene, and showed glucose-responsive production of insulin in hepatocytes. Permanent reversal of diabetes was characterized by glucose tolerance tests in the STZ-induced diabetic and autoimmune non-obese diabetic (NOD) mice [43].

Inherently glucose-responsive, liver-specific promoters have also been investigated with respect to insulin gene expression. Chen et al. demonstrated glucose-stimulated and insulin feedback regulated production of insulin in the liver of STZ-induced diabetic rats driven by the Glucose-6-phosphatase (G6Pase) promoter. They have reported amelioration of hyperglycemia $[44,45]$. Insulin expression by the G6Pase promoter was low in this approach due to negative feedback produced by insulin. Thus, further enhancement of this system has been suggested. The glucose-inducible, insulin-repressive GLUT2 promoter [46], and both glucose and insulin inducible insulin-1 promoter [47] have also been explored in the context of gene therapy.

Despite the above-mentioned data, the slow kinetics and latencies of transcriptionally regulated insulin secretory responses may result in a delay in correcting hyperglycemia and continuous production of insulin in the post induction phase can lead to hypoglycemia. Because plasma insulin has a short half-life, it might be possible to mimic insulin secretion by controlling the half-life of transgenic insulin mRNA. Thule PM, et al. [48] tested this hypothesis by creating an insulin construct producing a destabilized proinsulin message and compared the results with their standard construct. They showed that the construct producing a destabilized pro-insulin has improved glycemic responsiveness both in vitro and in vivo.

In a different approach, Gan SU, et al. [49] developed a Tet-inducible insulin expression system, as a safety mechanism to turn off insulin secretion in hypoglycemic conditions. They demonstrated that insulin gene expression can be turned off with doxycycline. Furthermore, they found that expression can be reactivated by withdrawing doxycycline in STZ-induced diabetic mice.

\section{Target cells for insulin transgene expression}

A variety of cell types have been targeted to produce insulin under insulin gene therapy, the characteristics of which are summarized in table 1.

Intestinal $\mathrm{K}$ cells possess some $\beta$ cell characteristics, such as expressing GLUT2, glucokinase, and proinsulin processing enzymes, and have drawn attention as a potential target for insulin gene therapy. For instance, Cheung At, et al. [50] cloned the human insulin gene under the control of a Glucose-regulated K cell-specific Promoter (GIP promoter), and when used in STZ-induced diabetic mice, resulted in the production of biologically active insulin and restoration of normoglycemia. However, concerns have been raised regarding the
Table 1: Characteristics of target cells for insulin gene therapy.

\begin{tabular}{|l|l|l|l|l|}
\hline \multirow{2}{*}{\multicolumn{1}{|c|}{ Characteristics }} & \multicolumn{4}{c|}{ Target cell } \\
\cline { 2 - 5 } & Liver & Muscle & Pituitary & K cells \\
\hline Glucose-sensing system & Yes & No & No & Yes \\
\hline Glucose-regulatable promoter & Yes & No & No & Yes \\
\hline Proinsulin processing enzymes & No & No & Yes & Yes \\
\hline Secretory system & No & No & Yes & Yes \\
\hline Derived from endodermal origin & Yes & No & No & No \\
\hline
\end{tabular}

regulation of the GIP promoter by sources other than glucose [51], accessibility of $\mathrm{K}$ cells by viral vectors, and cell-targeting difficulties related to the rapid turnover rate of $\mathrm{K}$ cells $[38,52]$.

Other cell types including pituitary cells and myocytes have also been examined as targets for insulin gene therapy. Early experiments of insulin gene therapy were carried out in the neuroendocrine cell line, AtT-20, which is derived from ACTH-secreting cells of the anterior pituitary. Moore HP, et al. [22] demonstrated that stable transfection of AtT- 20 cells with a plasmid containing the human proinsulin cDNA resulted in cell lines that secreted the correctly processed and mature insulin polypeptide. Although insulin secretion from AtT-20 cells can be stimulated by agents such as forskolin or isobutyl methylxanthine (IBMX), AtT-20 cells do not respond to glucose as a secretagogue. Hughes SD, et al. co-transfected the insulin gene with GLUT2 and glucokinase in AtT20 cells to achieve glucose-responsiveness [53]. However, the secretion of adrenocorticotropic hormone which stimulated glucocorticoid synthesis and inhibited insulin action limited the effectiveness of this approach. Genetic engineering of skeletal myocytes to counteract hyperglycemia was also tested. Skeletal myocytes do not express GLUT2 or glucokinase. Instead, they express GLUT4 and hexokinase, which each have a higher affinity (i.e., lower $\mathrm{Km}$ ) for glucose. Bosch and colleagues reversed hyperglycemia in STZ-induced diabetic mice by co-expression of insulin with glucokinase, progressing to experiments in dogs [54]. In 2017, the group demonstrated long-term efficacy of insulin gene therapy in dogs for up to 8 years [55].

Hepatocytes have long been a preferred target as sources of surrogate $\beta$ cells. They are long-lived and robust protein factories that are capable of the production and secretion of therapeutic proteins. Additionally, hepatocytes receive an extensive blood supply and are accessible by blood-borne particles, such as viruses. Moreover, they express the glucose-sensing molecules nearly identical to those in the pancreas (i.e., GLUT2, glucokinase), and thus have the intrinsic ability to respond to changes in blood glucose concentration. Finally, GIREs and glucose-sensitive gene promoters can be utilized to engineer insulin transgenes to be glucose concentration-sensitive. Although hepatocytes lack the proinsulin processing enzymes, this limitation has been largely overcome by various strategies. A number of researchers have transduced hepatocytes with an insulin gene [37-47].

\section{Methods for gene delivery}

Lasting and effective gene therapy requires efficient delivery of nucleic acid sequences to target cells, adequate and prolonged expression of the introduced gene, without any toxic side-effects. Gene delivery can be performed by many methods, including viral or nonviral vectors. 
Non-viral vectors have the advantages of safety, easy of manufacturing, and production scale, but are limited by inefficient delivery to target cells. Alam T, et al. [37] explored the potential of hydrodynamic delivery of insulin genes in the form of minicircle DNA. In STZ-induced diabetic rats, this approach corrected diabetic hyperglycemia in a dose-dependent fashion for about a month. The reduced immunogenicity of minicircle DNA allowed for repeated administration, with diminished efficiency after the first.

Other studies using non-viral vectors have also been reported. He CX, et al. [56] transferred an insulin expressing plasmid to STZinduced diabetic mice by hydrodynamic procedure. The delivery of the plasmid to the liver cells increased the plasma insulin levels and reduced the blood glucose levels. Niu L, et al. [57] transfected NIH3T3 cells in vitro with chitosan nanoparticles containing insulin plasmid and observed an increase in insulin levels. The in vivo administration of chitosan nanoparticles by lavage and coloclysis resulted in the reduction in blood glucose of STZ-induced diabetic rats after five days [58]. Similarly, Rasouli M and colleagues [59] used chitosan nanoparticles containing the insulin gene and investigated the ability of $\mathrm{K}$ and $\mathrm{L}$ cells to produce insulin in diabetic mice. The reduced blood glucose levels and increased insulin expression was observed. Sato M, et al. [60] administered a circular plasmid DNA which contained the Green Fluorescent Protein (GFP) gene, directly into the pancreatic parenchyma of ICR mice by electroporation. GFP was observed one day after gene delivery with its expression reduced to baseline within one week.

Viral vectors are the most efficient systems to deliver a gene into a cell. Wild-type virus is genetically modified to be rendered nonpathogenic and unable to replicate, while retaining infectivity. The most progress in vector development has been achieved using lentivirus, adenovirus and adeno-associated virus. Each viral vector type has its inherent advantages and disadvantages. The main types of viral vectors used for gene therapy are summarized in table 2 .

Retrovirus (RV) vectors have been used as viral vectors for insulin gene delivery. RV vectors are derived from disabled murine virus and are associated with many advantages such as stable integration into host chromosomal DNA and long-term expression of the gene. However, insertional mutagenesis presents a great risk. This risk was prominently noted in 1999 following the development of leukemia in patients treated for severe-combined immunodeficiency [61]. Another disadvantage of retroviral gene transfer is the requirement for target cells to be in an active state of proliferation. As most cells of the body are either non-dividing or slowly dividing, the potential utility of retroviral vectors for treatment of T1DM is limited $[62,63]$.

One type of retroviral vector, lentivirus (LV), is derived from the Human Immunodeficiency Virus (HIV) and has the advantage of being able to transduce both dividing and non-dividing cells. Due to their derivation from HIV, biosafety was a concern for their application as therapeutics; however, several modifications were introduced to reduce the possibility of producing replication-incompetent virus and improve safety [64].
LV has been used to deliver the insulin gene by Handorf AM, et al. [39] who expressed insulin under the control of the albumin promoter in the livers of STZ-induced diabetic rats. Insulin secretion in these rats was glucose-responsive and was maintained for 482 days while restoring weight gain in a dose-dependent fashion. Ren $B$ and colleagues [65] have also shown the long-term correction of hyperglycemia in STZ-induced diabetic rats and NOD mice [66] after the intraportal administration of lentiviral vector via unregulated expression of furin-cleavable insulin gene by using the Cytomegalovirus (CMV) promoter. However, predictably, the constitutive insulin secretion was not glucose responsive. Additionally, when the group used the same method for gene transfer to the liver of nine pancreatectomized pigs, only one pig maintained normoglycemia for a short-term [67].

Adenovirus constitutes another type of viral vector delivery. Adenoviral vectors have the ability to transduce both dividing and non-dividing cells with high efficiency and provide high levels of transgene expression with the ability to contain large transgenes. Adenoviral vectors do not integrate into the host genome [68]. Moreover, development of a strong cellular immune response to viral capsid proteins or in some cases the transgenes themselves; prevent long term gene expression of transgene as well as re-administration of the vector [68-71].

To address the immunogenicity of the viral capsid proteins, new generation of "gutless" adenovirus vectors have been developed. These vectors are completely devoid of all viral protein coding sequences and are therefore less immunogenic and known to have a prolonged expression of the transgene [71].

Handorf AM, et al. [38] used adenoviral vectors to transduce livers of STZ-induced diabetic rats with their insulin expression cassette. However, normoglycemia only persisted for about a month. Adenoviral vectors were also used by Short DK, et al. [72] to reverse hyperglycemia in diabetic mice. As expected, reduction in blood glucose levels were observed for about a month.

Adeno-associated Virus (AAV) vectors are becoming the preferred and most commonly used viral vectors for both research and clinical applications. They were first described about 50 years ago as a contaminant of adenoviral preparations, therefore named adenoassociated virus [73]. AAV is a helper-dependent parvovirus containing a single-stranded, linear DNA genome. They are non-pathogenic and can infect both dividing and non-dividing cells. In many cases the wild-type AAV genome integrates into a region of the chromosome in a site-specific manner. On the other hand, recombinant AAV (rAAV) vector integrates non-specifically into the host genome or might stay in the episomal state $[74,75]$.

One disadvantage of AAV is its relatively small packaging capacity $(4.7 \mathrm{~Kb})$, which limits the size of the transgene that can be inserted into it. However, the pre-proinsulin gene is small enough, so even when the gene is accompanied with multiple regulatory elements in a complex expression cassette, size limitation is unlikely to become an issue for applicability of the virus for gene transfer experiments.

Table 2: Examples of viral vectors used for insulin gene therapy.

\begin{tabular}{|c|c|c|c|c|c|}
\hline Vector Type & Packaging capacity & Transfers gene to nondividing cells & Expression & Chromosomal integration & Immunogenicity \\
\hline Adenovirus & $7.5 \mathrm{~kb}$ & Yes & Transient & No & High \\
\hline Adeno-associated virus & $4.5 \mathrm{~kb}$ & Yes & Transient and stable & No & Low \\
\hline Lentivirus & $8 \mathrm{~kb}$ & Yes & Stable & Yes & Low \\
\hline Retrovirus & $8 \mathrm{~kb}$ & No & Stable & Yes & Moderate \\
\hline
\end{tabular}


AAV's have been used by many researchers to successfully express insulin within non- $\beta$ cells. Since Sugiyama A, et al. [76] used an AAV vector to deliver the pre-proinsulin gene into the liver parenchyma of STZ-induced diabetic mice in 1997, the possible use of AAV vector to transfer the insulin gene in vivo as a gene delivery vector has been widely explored. Park et al. used AAV to deliver the insulin gene under control of the CMV promoter into STZ-induced diabetic rats and found improved glucose tolerance comparable to that of non-diabetic control rats. Additionally, they observed a less pronounced immune response using AAV when compared to the same treatment using adenoviral vectors [77]. Mas S, et al. [54] treated STZ-induced diabetic mice with insulin and glucokinase genes by using AAV vectors and observed normoglycemia, normalization of glucose tolerance, and metabolic parameters for four months. Gan SU, et al. [78] used AAV vectors to express the human proinsulin gene under a constitutive liver specific promoter to correct hyperglycemia in STZ-induced diabetic mice and achieved maintenance of euglycemia or a mild diabetic condition for 9 months accompanied by weight gain. Thulé PM, et al. [41] used self-complementary AAV vectors to express insulin transgenes in the liver of STZ-induced diabetic mice and observed variable glycemic responses. Jaén ML, et al. [55] treated two diabetic dogs with insulin and glucokinase genes by using AAV vectors and demonstrated long term insulin expression and therapeutic benefit.

One of the major hurdles facing AAV gene delivery is the host immune response. The host defense mechanism at the adaptive level is made up of cell-mediated and humoral immunity. Although AAV has not been associated with any known illnesses in the human and animal populations, most people are exposed to wild-type AAV early in life and are positive for anti-AAV antibodies $(>70 \%)$ for one or more serotypes [79]. The recombinant AAV capsid is very similar to the wild-type AAV. Thus, preexisting neutralizing antibodies against the wild-type AAV will limit vector transduction in tissues. Furthermore, even among individuals that lack preexisting anti-AAV antibodies, re-administration of the same AAV vector, should a second administration be required for treatment, is not likely to be effective.

Cell-mediated responses to AAV vectors also have been documented. Clinical trials showed that the cross-presentation of AAV capsids via major histocompatibility complex class I may be playing a role in the activation of Cytotoxic-T-lymphocyte (CTL) response [80]. Moreover, it is demonstrated that the anti-AAV CTL response is dose-dependent and could be potentially addressed by lowering the therapeutic dose with improved transduction efficiency and highly efficient AAV vectors [81].

Transduction efficiencies for AAV vectors are reported to be in the range from 25 to several hundred vector genome-containing particles per cell. This partly depends on AAV serotype and cell line, but also the wide range of methods used to generate adeno-associated vectors that have not been standardized. The increase in usage of rAAV vectors underscores the growing need for the development of suitable quality control methods for accurate vector characterization and standardization using a set of universally accepted standards. Given that the quality of rAAV preparations could be different depending on the specific criteria set by the investigator, it is very important to develop reliable and accurate functional dose determination methods.

\section{Concluding Remarks}

Despite the progress of transforming endogenous cells into surrogates of $\beta$ cells, the formation of fully functional cells perfectly replicating all aspects of endogenous $\beta$ cells has remained elusive. Insulin gene therapy must fulfill the prerequisite of adequate regulation, such that the insulin-producing surrogate cells should have the ability to respond to changing blood glucose levels by modulating insulin output. Although glucose responsive expression systems have achieved auto regulated insulin secretion to some degree, the crucial limitation of the relatively slow kinetics and the lag time involved in the secretory response must be addressed. It might be possible to control the half-life of transgenic insulin mRNA by incorporating specific elements into its sequence that result in rapid degradation. In addition, the combination of elements, such as the insertion of multiple copies of GIREs, might be used to create a more glucose-responsive insulin expression cassette.

One of the key issues remaining to be overcome before implementing insulin gene therapy in the clinical setting is to develop a highly efficient, specific and standardized gene delivery system. AAV vectors have emerged as one of the most promising vectors for insulin gene therapy. The biggest challenge facing AAV gene delivery is the host immune response, which is dose-dependent. This challenge may be addressed by combining the two avenues of improving the potency and purity of AAV vectors that posse's biological function, thus lowering the therapeutic dose for treatment, and a transient immunomosuppression at the time of treatment. Predictably reliable AAV vector based treatment outcomes, depend on our ability to prepare and purify high potency AAV vectors, and accurately quantitative its biological function.

Fortunately, there are many exciting and promising advances on the horizon of insulin gene therapy that we hope with continued research could be tenable for human translation.

\section{References}

1. Gillespie KM (2006) Type 1 diabetes: pathogenesis and prevention. CMAJ 175: 165-170.

2. Katsarou A, Gudbjörnsdottir S, Rawshani A, Dabelea D, Bonifacio E, et al. (2017) Type 1 diabetes mellitus. Nat Rev Dis Primers 3: 17016.

3. Centers for Disease Control and Prevention (2017) National Diabetes Statistics Report.

4. Imperatore G, Boyle JP, Thompson TJ, Case D, Dabelea D, et al. (2012) Projections of Type 1 and Type 2 Diabetes Burden in the U.S. Population Aged <20 Years Through 2050: dynamic modeling of incidence, mortality, and population growth. Diabetes Care 35: 2515-2520.

5. Dabelea D, Mayer-Davis EJ, Saydah S, Imperatore G, Linder B, et al. (2014) Prevalence of type 1 and type 2 diabetes among children and adolescents from 2001 to 2009. JAMA 311: 1778-1786.

6. Dieleman JL, Baral R, Birger M, Bui AL, Bulchis A, et al. (2016) US spending on personal health care and public health, 1996-2013. JAMA 316: 2627-2646.

7. American Diabetes Association (2018) Economic costs of diabetes in the U.S. in 2017. Diabetes Care 41: 917-928.

8. Banting FG, Best $\mathrm{CH}$ (2007) The internal secretion of the pancreas. 1922. Indian J Med Res 125: 251-266.

9. Gruessner RW, Gruessner AC (2013) The current state of pancreas transplantation. Nat Rev Endocrinol 9: 555-562.

10. Bruni A, Gala-Lopez B, Pepper AR, Abualhassan NS, Shapiro AJ (2014) Islet cell transplantation for the treatment of type 1 diabetes: recent advances and future challenges. Diabetes Metab Syndr Obes 7: 211-223.

11. Halban PA, German MS, Kahn SE, Weir GC (2010) Current Status of Islet Cell Replacement and Regeneration Therapy. J Clin Endocrinol Metab 95: 1034-1043. 
12. Hutton JC (1994) Insulin secretory granule biogenesis and the proinsulin-processing endopeptidases. Diabetologia 2: S48-S56.

13. Steiner DF (1998) The proprotein convertases. Curr Opin Chem Biol 2: 31-39.

14. Weiss M, Steiner DF, Philipson LH (2000) Insulin Biosynthesis, Secretion, Structure, and Structure-Activity Relationships.

15. Efrat S, Tal M, Lodish HF (1994) The pancreatic beta-cell glucose sensor. Trends Biochem Sci 19: 535-538.

16. Lederberg J (1963) Biological Future of Man. In: Wolstenholme G (Eds) Man and His Future. London 263-273.

17. Cotrim AP, Baum BJ (2008) Gene Therapy: Some History, Applications, Problems, and Prospects. Toxicol Pathol 36: 97-103.

18. Goeddel DV, Kleid DG, Bolivar F, Heyneker HL, Yansura DG, et al. (1979) Expression in Escherichia coli of chemically synthesized genes for human insulin. Proc Natl Acad Sci USA 76: 106-110.

19. Quianzon CC, Cheikh I (2012) History of insulin. J Community Hosp Intern Med Perspect 2.

20. Lomedico PT (1982) Use of recombinant DNA technology to program eucaryotic cells to synthesize rat proinsulin: a rapid expression assay for cloned genes. Proc Natl Acad Sci USA 79: 5798-5802.

21. Laub O, Rutter WJ (1983) Expression of the human insulin gene and cDNA in a heterologous mammalian system. J Biol Chem 258: 6043 6050.

22. Moore HP, Walker MD, Lee F, Kelly RB (1983) Expressing a human proinsulin cDNA in a mouse $\mathrm{ACTH}$-secreting cell: intracellular storage, proteolytic processing, and secretion on stimulation. Cell 35: 531-538.

23. Nicolau C, Le Pape A, Soriano P, Fargette F, Juhel MF (1983) In vivo expression of rat insulin after intravenous administration of the liposome-entrapped gene for rat insulin I. Proc Natl Acad Sci USA 80: 1068-1072.

24. Selden RF, Skośkiewicz MJ, Russell PS, Goodman HM (1987) Regulation of insulin-gene expression. Implications for gene therapy. N Engl J Med 317: 1067-1076.

25. Valera A, Fillat C, Costa C, Sabater J, Visa J, et al. (1994) Regulated expression of human insulin in the liver of transgenic mice corrects diabetic alterations. FASEB J 8: 440-447.

26. Groskreutz DJ, Sliwkowski MX, Gorman CM (1994) Genetically engineered proinsulin constitutively processed and secreted as mature, active insulin. J Biol Chem 269: 6241-6245.

27. Thulé PM, Liu J, Phillips LS (2000) Glucose regulated production of human insulin in rat hepatocytes. Gene Ther 7: 205-214.

28. Falqui L, Martinenghi S, Severini GM, Corbella P, Taglietti MV, et al. (1999) Reversal of diabetes in mice by implantation of human fibroblasts genetically engineered to release mature human insulin. Hum Gene Ther 10: 1753-1762.

29. Arcelloni C, Falqui L, Martinenghi S, Stabilini A, Pontiroli AE, et al. (2000) Processing and release of human proinsulin-cleavage products into culture media by different engineered non-endocrine cells: a specific assessment by capillary electrophoresis. J Endocrinol 166: 437-445.

30. Newgard CB, McGarry JD (1995) Metabolic coupling factors in pancreatic beta-cell signal transduction. Annu Rev Biochem 64: 689719.

31. Mueckler M, Thorens B (2013) The SLC2 (GLUT) Family of Membrane Transporters. Mol Aspects Med 34: 121-138.
32. Ishihara H, Wang H, Drewes LR, Wollheim CB (1999) Overexpression of monocarboxylate transporter and lactate dehydrogenase alters insulin secretory responses to pyruvate and lactate in beta cells. J Clin Invest 104: 1621-1629.

33. Towle HC (2005) Glucose as a regulator of eukaryotic gene transcription. Trends Endocrinol Metab 16: 489-494.

34. Shih HM, Towle HC (1992) Definition of the carbohydrate response element of the rat S14 gene. Evidence for a common factor required for carbohydrate regulation of hepatic genes. J Biol Chem 267: 13222-13228.

35. Shih HM, Liu Z, Towle HC (1995) Two CACGTG motifs with proper spacing dictate the carbohydrate regulation of hepatic gene transcription. J Biol Chem 270: 21991-21997.

36. Cuif MH, Cognet M, Boquet D, Tremp G, Kahn A, et al. (1992) Elements responsible for hormonal control and tissue specificity of L-type pyruvate kinase gene expression in transgenic mice. Mol Cell Biol 12: 4852-4861.

37. Alam T, Wai P, Held D, Vakili ST, Forsberg E, et al. (2013) Correction of diabetic hyperglycemia and amelioration of metabolic anomalies by minicircle DNA mediated glucose-dependent hepatic insulin production. PLoS One 8: e67515.

38. Handorf AM, Sollinger HW, Alam T (2015) Insulin gene therapy for type 1 diabetes mellitus. Exp Clin Transplant 1: 37-45.

39. Handorf AM, Sollinger HW, Alam T (2017) Long-term correction of diabetic hyperglycemia through glucose responsive hepatic insulin production using lentivirus. J Diabetol Endocrinol 2: 1-10.

40. Thulé PM, Liu JM (2000) Regulated hepatic insulin gene therapy of STZ-diabetic rats. Gene Ther 7: 1744-1752.

41. Thulé PM, Campbell AG, Jia D, Lin Y, You S, et al. (2015) Long-term glycemic control with hepatic insulin gene therapy in streptozotocindiabetic mice. J Gene Med 17: 141-152.

42. Han J, McLane B, Kim EH, Yoon JW, Jun HS (2011) Remission of diabetes by insulin gene therapy using a hepatocyte-specific and glucose-responsive synthetic promoter. Mol Ther 19: 470-478.

43. Zhang T, Dong HH (2014) Glucose-regulated insulin production in the liver improves glycemic control in type 1 diabetic mice. Mol Metab 4: 70-76.

44. Chen R, Meseck M, McEvoy RC, Woo SL (2000) Glucose-stimulated and self-limiting insulin production by glucose 6-phosphatase promoter driven insulin expression in hepatoma cells. Gene Ther 7: 1802-1809.

45. Chen R, Meseck ML, Woo SLC (2001) Auto-regulated hepatic insulin gene expression in type 1 diabetic rats. Mol Ther 3: 584-590.

46. Burkhardt BR, Parker MJ, Zhang YC, Song $\mathrm{S}$, Wasserfall $\mathrm{CH}$, et al. (2005) Glucose transporter-2 (GLUT2) promoter mediated transgenic insulin production reduces hyperglycemia in diabetic mice. FEBS Lett 579: 5759-5764.

47. Hsu PY, Kotin RM, Yang YW (2008) Glucose- and metabolically regulated hepatic insulin gene therapy for diabetes. Pharm Res 25: 1460-1468.

48. Thulé PM, Lin Y, Jia D, Olson DE, Thang SC, et al. (2017) mRNA destabilization improves glycemic responsiveness of transcriptionally regulated hepatic insulin gene therapy in vitro and in vivo. J Gene Med 19.

49. Gan SU, Fu Z, Sia KC, Kon OL, Calne R, et al. (2019) Development of a liver-specific Tet-off AAV8 vector for improved safety of insulin gene therapy for diabetes. J Gene Med 21: e3067. 
50. Cheung AT, Dayanandan B, Lewis JT, Korbutt GS, Rajotte RV, et al. (2000) Glucose-dependent insulin release from genetically engineered K cells. Science 290: 1959-1962.

51. Yamane S, Harada N, Inagaki N (2016) Mechanisms of fat-induced gastric inhibitory polypeptide/glucose-dependent insulinotropic polypeptide secretion from K cells. J Diabetes Investig 1: 20-26.

52. Dong H, Woo SL (2001) Hepatic insulin production for type 1 diabetes. Trends Endocrinol Metab 12: 441-446.

53. Hughes SD, Quaade C, Johnson JH, Ferber S, Newgard CB (1993) Transfection of AtT-20ins cells with GLUT-2 but not GLUT-1 confers glucose-stimulated insulin secretion. Relationship to glucose metabolism. J Biol Chem 268: 15205-15212.

54. Mas A, Montané J, Anguela XM, Muñoz S, Douar AM, et al. (2006) Reversal of type 1 diabetes by engineering a glucose sensor in skeletal muscle. Diabetes 55: 1546-1553.

55. Jaén ML, Vilà L, Elias I, Jimenez V, Rodó J, et al. (2017) Long-Term Efficacy and Safety of Insulin and Glucokinase Gene Therapy for Diabetes: 8-Year Follow-Up in Dogs. Mol Ther Methods Clin Dev 6: 1-7.

56. He CX, Shi D, Wu WJ, Ding YF, Feng DM, et al. (2004) Insulin expression in livers of diabetic mice mediated by hydrodynamicsbased administration. World J. Gastroenterol 10: 567-572.

57. Niu L, Xu YC, Xie HY, Dai Z, Tang HQ (2008) Expression of human insulin gene wrapped with chitosan nanoparticles in NIH3T3 cells and diabetic rats. Acta Pharmacol Sin 29: 1342-1349.

58. Niu L, Xu YC, Dai Z, Tang HQ (2008) Gene therapy for Type 1 diabetes mellitus in rats by gastrointestinal administration of chitosan nanoparticles containing human insulin gene. World J Gastroenterol 14: 4209-4215.

59. Rasouli M, Allaudin ZN, Omar AR, Ahmad Z (2013) Insulin secreted from genetically engineered intestinal cells reduces blood glucose levels in diabetic mice. Curr Gene Ther 13: 229-239.

60. Sato M, Inada E, Saitoh I, Ohtsuka M, Nakamura S, et al. (2013) Sitetargeted non-viral gene delivery by direct DNA injection into the pancreatic parenchyma and subsequent in vivo electroporation in mice. Biotechnol J 8: 1355-1361.

61. Cavazzana-Calvo M, Hacein-Bey S, de Saint Basile G, Gross $F$ Yvon E, et al. (2000) Gene therapy of human severe combined immunodeficiency (SCID)-X1 disease. Science 288: 669-672.

62. Kolodka TM, Finegold M, Moss L, Woo SL (1995) Gene therapy for diabetes mellitus in rats by hepatic expression of insulin. Proc Natl Acad Sci USA 92: 3293-3297.

63. Muzzin P, Eisensmith RC, Copeland KC, Woo SL (1997) Hepatic insulin gene expression as treatment for type 1 diabetes mellitus in rats. Mol Endocrinol 11: 833-837.

64. Zufferey R, Dull T, Mandel RJ, Bukovsky A, Quiroz D, et al. (1998) Self-inactivating lentivirus vector for safe and efficient in vivo gene delivery. J Virol 72: 9873-9880.

65. Ren B, O'Brien BA, Swan MA, Koina ME, Nassif N, et al. (2007) Longterm correction of diabetes in rats after lentiviral hepatic insulin gene therapy. Diabetologia 50: 1910-1920.
66. Ren B, O'Brien BA, Byrne MR, Ch'ng E, Gatt PN, et al. (2013) Longterm reversal of diabetes in non-obese diabetic mice by liverdirected gene therapy. J Gene Med 15: 28-41.

67. Gerace D, Ren B, Hawthorne WJ, Byrne MR, Phillips PM, et al. (2013) Pancreatic transdifferentiation in porcine liver following lentiviral delivery of human furin-cleavable insulin. Transplant Proc 45: 18691874.

68. Volpers C, Kochanek S (2004) Adenoviral vectors for gene transfer and therapy. J Gene Med 6: S164-S171.

69. Wold WS, Doronin K, Toth K, Kuppuswamy M, Lichtenstein DL, et al. (1999) Immune responses to adenoviruses: viral evasion mechanisms and their implications for the clinic. Curr Opin Immunol 11: 380-386.

70. McCaffrey AP, Fawcett $P$, Nakai H, McCaffrey RL, Ehrhardt A, et al. (2008) The host response to adenovirus, helper-dependent adenovirus, and adeno-associated virus in mouse liver. Mol Ther 16: 931-941.

71. Alba R, Bosch A, Chillon M (2005) Gutless adenovirus: last-generation adenovirus for gene therapy. Gene Ther 12: S18-S27.

72. Short DK, Okada S, Yamauchi K, Pessin JE (1998) Adenovirusmediated transfer of a modified human proinsulin gene reverses hyperglycemia in diabetic mice. Am J Physiol 275: E748-E756.

73. Atchison RW, Casto BC, Hammon WM (1965) Adenovirus-associated defective virus particles. Science 149: 754-756.

74. McCarty DM, Young SM Jr, Samulski RJ (2004) Integration of adenoassociated virus (AAV) and recombinant AAV vectors. Annu Rev Genet 38: 819-845.

75. Deyle DR, Russell DW (2009) Adeno-associated virus vector integration. Curr Opin Mol Ther 11: 442-447.

76. Sugiyama A, Hattori S, Tanaka S, Isoda F, Kleopoulos S, et al. (1997) Defective adenoassociated viral-mediated transfection of insulin gene by direct injection into liver parenchyma decreases blood glucose of diabetic mice. Horm Metab Res 29: 599-603.

77. Park YM, Woo S, Lee GT, Ko JY, Lee Y, et al. (2005) Safety and efficacy of adeno-associated viral vector-mediated insulin gene transfer via portal vein to the livers of streptozotocin-induced diabetic SpragueDawley rats. J Gene Med 7: 621-629.

78. Gan SU, Notaridou M, Fu ZY, Lee KO, Sia KC, et al. (2016) Correction of Murine Diabetic Hyperglycaemia With A Single Systemic Administration of An AAV2/8 Vector Containing A Novel Codon Optimized Human Insulin Gene. Curr Gene Ther 16: 65-72.

79. Boutin S, Monteilhet V, Veron $\mathrm{P}$, Leborgne $\mathrm{C}$, Benveniste $\mathrm{O}$, et al. (2010) Prevalence of serum IgG and neutralizing factors against adeno-associated virus (AAV) types 1, 2, 5, 6, 8, and 9 in the healthy population: implications for gene therapy using AAV vectors. Hum Gene Ther 21: 704-712.

80. Nathwani AC, Tuddenham EGD, Rangarajan S, Rosales C, Mclntosh $\mathrm{J}$, et al. (2011) Adenovirus-associated virus vector-mediated gene transfer in hemophilia B. N Engl J Med 365: 2357-2365.

81. Manno CS, Pierce GF, Arruda VR, Glader B, Ragni M, et al. (2006) Successful transduction of liver in hemophilia by AAV-Factor IX and limitations imposed by the host immune response. Nat Med 12: 342-347. 